\title{
Candidial Infection in Pre - Term Babies- A Clinical Study
}

\author{
Venkatesh $\mathrm{G}^{1}$, Arun Kumar $\mathrm{P}^{2}$ \\ 1,2DM Neonatology Resident, Dept of neonatology, ICH and IOG, MMC, Chennai-08, Tamil Nadu.
}

\section{Abstract}

Background: Invasive candidiasis in neonates is a serious and common cause oflate onset sepsis and has a high mortality. The present study was conducted to assess candidial infection in pre- term babies. Subject and Method: The present study was conducted in the Department of Neonatology. It comprised of 56 low birth weight babies of both genders. In all cases, gestational age, birth weight, length of stay before candidemia, presence of CVC, stay in NICU $\leq 7$ days and mechanical ventilation was recorded. Result: Out of 56 patients, boys were 32 and girls were 24. Gestational age (weeks) was 30.2, birth weight was 1214.5 grams, length of stay before candidemia was 10.2 days, presence of CVC in 54, stay in NICU $\leq 7$ days was seen in 52 and mechanical ventilation was seen in 47 . Clinical manifestations was candida endophthalmitis in 13, candida endocarditis in 16 and congenital cutaneous candidiasis in 27. The difference was significant (P< 0.05). Conclusion: Authors found that Candidial infection is common in newborn. Clinical manifestations were candida endophthalmitis, candida endocarditis and congenital cutaneous candidiasis.

Keywords: Babies, Candida endophthalmitis, Pre- term.

Corresponding Author: Dr. Arun Kumar P, DM Neonatology Resident, Dept of neonatology, ICH and IOG, MMC, Chennai-08, Tamil Nadu. Email: venkathpt2000@gmail.com

Received: January 2020

Accepted: January 2020

\section{Introduction}

Candidiasis refers to infection with fungi of the genus Candida. Candidemia is presence of Candida fungi in the blood. Catheter-related candidemia refers to candidemia that resolves rapidly after catheter removal and initiation of therapy. Disseminated, or invasive, candidiasis refers to persistent infection after removal of a catheter and/or isolation of Candida from other normally sterile body sites. $^{[1,2]}$

Invasive candidiasis in neonates is a serious and common cause oflate onset sepsis and has a high mortality (25 to $35 \%)$. The incidence of such fungal infections has increased 11 fold over the past 15 years. Candida species are the 3rd most frequent organism (after coagulase negative Staph. and Staph. aureus) isolated in late onset sepsis in very low birth weight infants. ${ }^{[3]}$

Although blood stream infection (BSI) due to Candida species (spp.) in the neonatal intensive care unit (NICU) isless frequent than that due to Gram-positive or Gramnegative bacteria, it has higher morbidity and mortality rates. ${ }^{[4]}$ Risk factors for neonatal candidemia include prematurity, use of central venous lines, endotracheal tubes, parenteral nutrition, broad-spectrum antibiotic administration (especially third-generation cephalosporins), prolonged hospitalization, abdominal surgery, exposure to $\mathrm{H} 2$ blockers, and Candidacolonization. Although Candida albicans is the most prevalent yeast pathogen, BSIs caused by Candida non-albicans, particularly Candida parapsilosis complex and Candidaglabrata complex, have increased in recent years. ${ }^{[5]}$ The present study was conducted to assess candidial infection in pre- term babies.

\section{Subjects and Methods}

The present study was conducted in the Department of Neonatology. It comprised of 56 low birth weight babies of both genders. The study was approved from institutional ethical committee.

In all cases, gestational age, birth weight, length of stay before candidemia, presence of $\mathrm{CVC}$, stay in $\mathrm{NICU} \leq 7$ days and mechanical ventilation was recorded. Results thus obtained were subjected to statistical analysis. P value less than 0.05 was considered significant.

\section{Results}

Table 1: Distribution of patients

\begin{tabular}{|l|l|l|}
\hline \multicolumn{3}{|c|}{ Total- 56 } \\
\hline Gender & Boys & Girls \\
\hline Number & 32 & 24 \\
\hline
\end{tabular}

[Table 1] shows that out of 56 patients, boys were 32 and girls were 24 .

[Table 2] shows that gestational age (weeks) was 30.2, birth 


\section{Venkatesh \& Arun; Candidial Infection in Pre - Term Balies}

weight was 1214.5 grams, length of stay before candidemia was 10.2 days, presence of CVC in 54, stay in NICU $\leq 7$ days was seen in 52 and mechanical ventilation was seen in 47.

\begin{tabular}{|c|c|}
\hline Characteristics & Number \\
\hline Mean Gestational age (weeks) & 30.2 \\
\hline Mean Birth weight (grams) & 1214.5 \\
\hline Mean Length of stay before candidemia & 10.2 \\
\hline Presence of CVC & 54 \\
\hline Stay in NICU $\leq 7$ days & 52 \\
\hline Mechanical ventilation & 47 \\
\hline
\end{tabular}

Table 3: Clinical manifestations

\begin{tabular}{|l|l|l|}
\hline Clinical manifestations & Number & P value \\
\hline Candida endophthalmitis & 13 & \multirow{2}{*}{0.01} \\
\cline { 1 - 2 } Candida endocarditis & 16 & \\
\cline { 1 - 2 } Congenital cutaneous candidiasis & 27 & \\
\hline
\end{tabular}

[Table 3], graph I shows that clinical manifestations was candida endophthalmitis in 13, candida endocarditis in 16 and congenital cutaneous candidiasis in 27. The difference was significant $(\mathrm{P}<0.05)$.

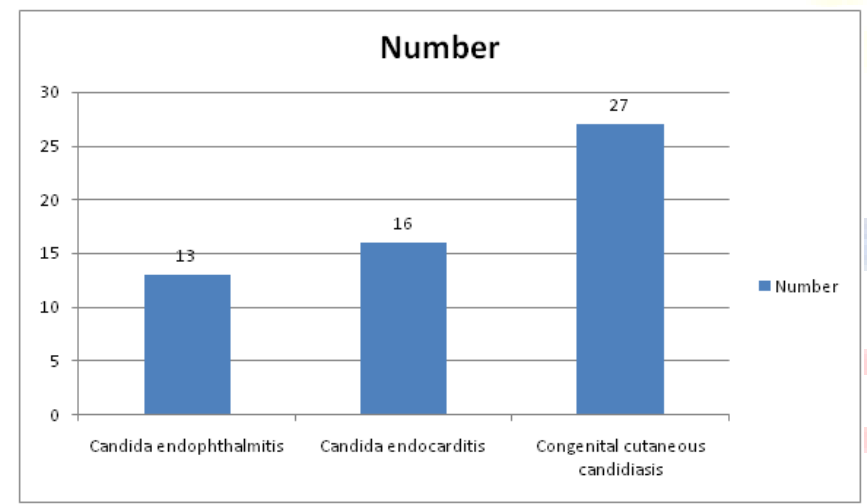

Figure 1: Clinical manifestations

\section{Discussion}

Preterm infants are predisposed to Candida infections because of immaturity of their immune system and invasive interventions. ${ }^{[6]}$ Transmission of Candida may be vertical (from maternal vaginal infection) or nosocomial. ${ }^{[7]}$ Colonization of health workers is as high as $30 \%$. Initial site of colonization is usually the gastrointestinal tract. Risk factors for candidiasis include: a) low birth weight (use of broad spectrum and/or multiple antibiotics; c) central venous catheters; d) parenteral alimentation and intravenous fat emulsion; e) colonization with Candida and/or previous episode of mucocutaneous candidiasis. ${ }^{[8]}$ The present study was conducted to assess candidial infection in preterm babies.

In present study, out of 56 patients, boys were 32 and girls were 24. Zaoutis et $\mathrm{al}^{[9]}$ found that cumulative incidence rates of IC were $4.2 \%, 2.2 \%$ and $1.5 \%$ for birth-weight categories $<750 \mathrm{~g},<1000 \mathrm{~g},<1500 \mathrm{~g}$, respectively. Forty nine infants with IC and 90 controls were enrolled. Necrotizing enterocolitis (NEC) was the only independent risk factor for IC $(\mathrm{p}=0.03)$. CNS candidiasis occurred in $50 \%$ of evaluated infants, while congenitalcandidiasis occurred in $31 \%$. Infants with CNS candidiasis had a higher mortality rate $(57 \%)$ and incidence of deafness $(50 \%)$ than the overall cohort of infants with IC. NDI (56\% vs. 33\%; p = $0.017)$ and death (45\% vs. $7 \% ; \mathrm{p}=0.0001)$ weremore likely in cases than in controls, respectively. IC survivors were more likely to be deaf $(28 \%$ vs. $7 \%$; $p=0.01)$. IC independently predicted mortality $(\mathrm{p}=0.0004)$ and NDI $(\mathrm{p}=$ 0.018).

We found that gestational age (weeks) was 30.2, birth weight was 1214.5 grams, length of stay before candidemia was 10.2 days, presence of CVC in 54, stay in $\mathrm{NICU} \leq 7$ days was seen in 52 and mechanical ventilation was seen in 47. Clinical manifestations was candida endophthalmitis in 13, candida endocarditis in 16 and congenital cutaneous candidiasis in 27.

Fernandez et $\mathrm{al}^{[10]}$ conducted a study in which forty-one candidemia cases were reviewed (overall incidence, 3.0 per 100 admissions). Candida parapsilosis sensu stricto $(58.5 \%)$ and C. albicans $(34.1 \%)$ were the most common species recovered. A variable drift through years was observed; in $2015,75 \%$ of the cases were caused by non-albicans species. The duration of NICU hospitalization of patients with non-albicans was significantly longer than in those with C. albicans (median days, 10 versus 12). Patients with nonalbicans species were more likely to have parenteral nutrition than those with C. albicans (96.3\% versus $71.4 \%$ ). Candida albicans was the dominant species in Europe and America (median, 55\% and 60\%; resp.); non-albicans species predominate in Asia (75\%). Significant geographic variation is evident among cases of candidemia in different parts of the world, recognizing the importance of epidemiological data to facilitate the treatment.

\section{Conclusion}

Authors found that Candidial infection is common in newborn. Clinical manifestations was candida endophthalmitis, candida endocarditis and congenital cutaneous candidiasis.

\section{References}

1. Friedman S, Richardson SE, Jacobs SE, O’Brien K: Systemic Candida infection in extremely low birth weight infants: short term morbidity and long term neurodevelopmental outcome. Pediatr Infect Dis J 2000, 19(6):499-504.

2. Stoll BJ, Hansen NI, Nellie I, Adams-Chapman I, Fanaroff AA, Hintz SR, Vohr B, Higgins RD: Neurodevelopmental and growth impairment among extremely Low-birth-weight infants with neonatal infection. J Am Med Assoc 2004, 292(19):2357.

3. Clerihew L, Lamagni TL, Brocklehurst P, McGuire W: Invasive fungal infection in very low birthweight infants: National Prospective Surveillance Study. Arch Dis Child Fetal Neonatal 2006, 


\section{Venkatesh d Arun; Candidial Infection in Pre - Jerm Babies}

91(3):188-192.

4. Benjamin DK Jr, Stoll BJ, Fanaroff AA, McDonald SA, Oh W, Higgins RD, Duara S, Poole K, Laptook A, Goldberg R: Neonatal candidiasis among extremely low birth weight infants: risk factors, mortality rates, and neurodevelopmental outcomes at 18 to 22 months. Pediatrics 2006, 117(1):84-92.

5. Adams-Chapman et al. Neurodevelopmental outcome of extremely Low birth weight infants with Candida infection. J Pediatr 2013, 163(4):961-967.963.

6. Greenberg R, Benjamin DK Jr, Gantz MG, Cotten CM, Stoll BJ, Walsh MC, Goldberg RN, Smith PB: Empiric antifungal therapy and outcomes in extremely Low birth weight infants with invasive candidiasis. J Pediatr 2012, 161(2):264-269.

7. Bzoch KR, League R, Brown VL: Receptive Expressive Emergent LanguageTest. In Austin, TX: PRO-ED; 2003.

8. Ascher SB, Smith PB, Watt K, Benjamin DK, Cohen-Wolkowiez M, Clark RH,Benjamin DK Jr, Moran C: Antifungal therapy and outcomes in infantswith invasive Candida infections. Pediatr Infect
Dis J 2012, 31(5):439-443.

9. Zaoutis TE, Heydon K, Localio R, Walsh TJ, Feudtner C: Outcomesattributable to neonatal candidiasis. Clin Infect Dis 2007, 44(9):1187-1193.

10. Fernandez M, Moylett EH, Noyola DE, Baker CJ: Candidal meningitis inneonates: A 10-year review. Clin Infect Dis 2000, 31(2):458-463.

Copyright: () the author(s), 2020. It is an open-access article distributed under the terms of the Creative Commons Attribution License (CC BY 4.0), which permits authors to retain ownership of the copyright for their content, and allow anyone to download, reuse, reprint, modify, distribute and/or copy the content as long as the original authors and source are cited.

How to cite this article: Venkatesh G, Arun Kumar P. Candidial Infection in Pre- Term Babies- A Clinical Study. Asian J. Clin. Pediatr. Neonatol.2020;8(1):82-84.

DOI: dx.doi.org/10.47009/ajcpn.2020.8.1.19

Source of Support: Nil, Conflict of Interest: None declared.
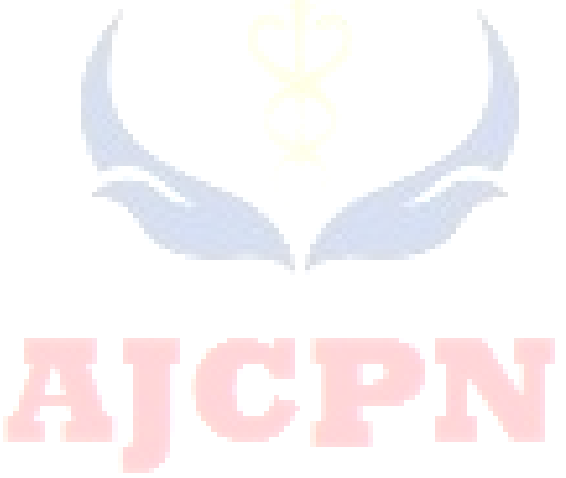